\title{
The effect of early adoption of an academic electronic health record system in nursing education: A pilot outcome study
}

\author{
Joohyun, Chung*1, Teresa Reynolds² \\ ${ }^{1}$ College of Nursing, University of Massachusetts Amherst, Amherst, MA, USA \\ ${ }^{2}$ College of Nursing, University of Massachusetts Dartmouth, Dartmouth, MA, USA
}

Received: July 22, 2020

DOI: $10.5430 /$ jnep.v11n5p16
Accepted: October 31, $2020 \quad$ Online Published: January 13, 2021

URL: https://doi.org/10.5430/jnep.v11n5p16

\begin{abstract}
Objective: This study aimed to explore the faculty's and students' perceptions of an academic electronic health record system (AEHRs) for teaching/learning electronic nursing documentation and to assess the outcomes of the AEHRs on nursing students' competency with electronic nursing documentation.

Methods: With a mixed-method pilot study, a convenience sample of 41 undergraduate nursing students and a purposive sample of 7 faculty and 9 students were used. Two groups of student participants for the quantitative data were compared for their competency with electronic nursing documentation. For the qualitative data, an in-depth, exploratory approach to data collection was taken for the nursing faculty and the intervention group.

Results: For the quantitative findings, the early adoption of an AEHRs could help students to collect a patients' health information through the system even though it may not impact their critical thinking on a patient's care. For the qualitative findings, three key themes were shared by the faculty and students: (1) benefits and challenges, (2) impact of the AEHRs, and (3) recommendations for future adoption.

Conclusions: This study revealed that the successful adoption of an AEHRs includes many steps that can be used to create positive improvements. These findings were beneficial to prepare students and nursing educators for the future of health information technology. Meaningful adoption of an AEHRs will help in building the competence of undergraduate nursing students in electronic nursing documentation and improve patient care.
\end{abstract}

Key Words: Electronic nursing documentation, Electronic health records system, An academic electronic health record system

\section{INTRODUCTION}

With the benefits of electronic health record systems (EHRs), nearly all reported hospitals (96\%) possessed a certified EHR technology in 2017. ${ }^{[1]}$ The broad adoption of EHRs has been led to several movements in nursing education. The Technology Informatics Guiding Education Reform (TIGER) initiative offered tools and resources for students to advance their skills and for educators to develop technology and health informatics in nursing education in order to improve patient care. ${ }^{[2]}$ Quality and Safety Education for Nurses (QSEN) faculty and a National Advisory Board have recommended informatics as nursing faculty should incorporate informatics into all levels of the curriculum. ${ }^{[3,4]}$ As part of informatics, an academic electronic health record system (AEHRs) is

\footnotetext{
*Correspondence: Joohyun, Chung; Email: joohyunchung@ umass.edu; Address: College of Nursing, University of Massachusetts Amherst, 224 Skinner Hall, 651 North Pleasant Street, Amherst, MA 01003, USA.
} 
adopted to provide students' learning opportunities through patient assessment and decision making. ${ }^{[5-8]}$ Specifically, AEHRs can help students how to utilize standard nursing terminology, how to incorporate clinical documentation from various sources, how to support standard care plans, guidelines, and protocols, and how to support drug interaction checking, and linking clinical tasks. ${ }^{[7,9,10]}$ However, nurse educators have been faced with several challenges to meet the expectation of graduate nurses' competency to use AEHRs for synthesizing knowledge in patient care. The barriers include the Internet connectivity at the clinical laboratory, ${ }^{[5]}$ the small group of nursing faculty involved in integrating AEHRs, ${ }^{[9]}$ lack of resources, including IT support and faculty development. ${ }^{[7]}$ In order to ensure adequate preparation for meaningful use within the EHRs, integrating an AEHRs into the curriculum is no longer optional for nursing faculty. ${ }^{[7,11]}$

In 2016, AEHRs was adopted into the Accelerated Bachelor of Science (ABS) program at one university in the eastern United States. We believed the AEHRs could create a productive environment for nursing students to interact with the EHR system while they were learning specific nursing content related to electronic documentation (e.g., health assessment and fundamental nursing care).

The aims of this study were twofold: (1) to explore the faculty's and students' perceptions of introducing AEHRs for teaching/learning electronic nursing documentation and (2) to assess the outcomes of the AEHRs on nursing students' competency with electronic nursing documentation.

The NLN/Jeffries Simulation Framework ${ }^{[12]}$ was utilized to assess the outcomes of AEHRs on nursing students' competency with electronic nursing documentation. The framework provides five constructs (Teacher, Student, Educational Practices, Outcomes, and Simulation Design Characteristics). Specifically, the concept of "simulation" was defined as the use of AEHRs in this study.

\section{Methods}

\subsection{Study design}

A mixed-method pilot study design was used as the first step of the adoption of AHERs into all undergraduate nursing programs. This pilot study was only implemented AEHRs in the ABS program with a smaller size study: 1) a non-equivalent control group posttest-only research design was used to compare nursing students' competency with electronic nursing documentation between those who were enrolled in the program that utilized AEHRs and those who were enrolled in the program that did not utilize AEHRs, and 2) a qualitative descriptive research design was applied to assess the acceptability of the adoption of AHERs through describing both faculty and students' perceptions of AEHRs in terms of electronic nursing documentation.

\subsection{Sample and setting}

For the quantitative data, a convenience sample of 41 nursing students (34 students from the Bachelor of Nursing (BS) program), and 7 students from the Accelerated Bachelor of Science (ABS) was used, although the entire cohort of the BS $(N=98)$ and the ABS group $(\mathrm{N}=9)$ were invited in this study. Inclusion criteria were as follows: students who had been admitted into an undergraduate nursing program (either BS or ABS) and had taken or been taking a "fundamental nursing didactic course and clinical lab" and "health assessment didactic course and clinical lab" within the last five months. A power of 0.80 , an alpha level of 0.05 , and a medium effect size 0.50 revealed a required sample size of 64 participants in each of the groups for a total of 128 participants using G power. ${ }^{[13]}$ Due to the small sample size in this study, it was not sufficient enough to maintain the statistical power for the primary outcome. For the qualitative data, a purposive sample of faculty $(\mathrm{N}=7)$ and students $(\mathrm{N}=9)$ was used. The inclusion criteria for faculty and students were to have taught or taken any undergraduate nursing courses in the ABS program that had AEHRs during the 2016-2017 academic year. The sample size for the qualitative data was considered as an adequate sample because of full participation from both faculty $(\mathrm{N}=7)$ and students $(\mathrm{N}=9)$ in the ABS group. All seven faculty who had taught a course in the ABS program participated in the interview, and all nine students in the ABS program participated in a focus group. Focus groups are typically made up of 6 to 12 invidious. ${ }^{[14]}$

\subsection{Intervention}

The intervention group was made up of students in the ABS program that had adopted AEHRs within their curriculum. This addition had provided nursing students with electronic nursing documentation skills based on aspects of the EHR system in acute care settings. Of the seven faculty members who taught nursing courses in the ABS program, three had utilized the AEHRs in their class (e.g., assignments and in-class activities). The intervention was provided during the second term (Spring 2018) in the ABS program. The control group was comprised of students in the BS program, which had not offered AEHRs within their nursing curriculum. Both the BS and the ABS program have the same curriculum except for the different timeline (ABS: 5 terms (one and half years) vs. BS: 4 years). For example, the second term in the ABS program is equivalent to the second year of the BS program. 


\subsection{Data collection}

In this study, the decision of the adoption of an AEHRs in the ABS group was made by the body of faculty in the 2016 Spring semester. An AEHRs was adopted in the ABS group, 2016 Fall semester. After approval from the institutional review board (IRB) at the participating university, the competency with electronic nursing documentation was compared between the beginning of the third term in the ABS program and the third year of the BS program. Student participants for the quantitative data were evaluated for their competence with electronic nursing documentation, and the two groups (BS and ABS) were compared using AEHRs, specifically Docucare (Lippincott), at the computer lab.

At the beginning of the meeting with the student participants, the author explained the purpose of the study, how it would be carried out, and what they were expected to do. Notably, the participating BS students were not given any instruction for using DocuCare, AEHRs, although participating ABS students were exposed previously for using DocuCare. Both the BS and ABS students were asked to review the patient information using one AEHRs at the computer lab. First participating students were asked to review one patient's information on Docucare. The case was a 56-year old female with a history of diabetes mellitus, hypertension, and hyperlipidemia. She presented to the emergency room for a foot wound. She was unaware that she feels infected. She has just been admitted to the medical-surgical unit. All patient information was available on Docucare, such as demographic information, admission data, health history, lab data, medication, physician's order list, and nurses' notes. "Pre-worksheet" was given to students. Using the information through the Docucare, students were asked to fill in the Pre-worksheet, using electronic formatting that was built into Google Forms (as one type of online survey). The pre-worksheet has two parts: (1) Roots and (2) Impression. Roots include background and physiology, subjective findings, objective findings, recent lab results, and medications. Impression includes questions such as What are the issues with this patient? What are your priorities when you enter the room? What is your plan? The students conceptualized the patient information through AEHRs, and they completed the pre-worksheet. Four evaluating nursing faculty independently assessed the pre-worksheets using the Competency of Electronic Nursing Documentation scale (CEND). Each participant spent to complete "pre-worksheet" for an average of 21 minutes, ranging from 5-45 minutes. Four nursing faculty members reviewed the case used for student participants. The four nursing faculty members used the CEND to independently evaluate the nursing documentation and critical thinking of the student participants' completed pre worksheet. The student identities were not known to the evaluating faculty.

For the qualitative data, an in-depth, exploratory approach to data collection was taken for the nursing faculty, employing semi-structured interview questions. Additionally, demographic information was collected, including gender, age, and the number of years teaching in nursing. For the ABS students, the focus group discussion was led by the PI and the co-PI.

\subsection{Outcome measures}

The primary outcome was assessed with the Competency of Electronic Nursing Documentation in Nursing Education (CEND). ${ }^{[15]}$ The CEND was a total 8-item tool, using the 5-point Likert system. The CEND was developed to include the two constructs in nursing, such as the data collection and the clinical reasoning process components of competency with electronic nursing documentation. ${ }^{[15]}$ Definitions of the collection of data are to combine knowledge and experience with the collection of data about the patient's situation. The second construct is a clinical reasoning process through the system for meaningful use of the electronic nursing documentation system in nursing education. A panel of experts reviewed the tool for content validity. The experts offered comments and suggestions. A three-point ordinal Likert rating scale was used to evaluate the content validity of each of the items, specifically regarding necessity, relevance, clarity, and simplicity. The content validity index calculated for the scale was determined as 0.93 . The exploratory factor analysis (EFA) was used for the investigation of construct validity. The results of EFA produced two factors: assessment skills through the system (3 items) and Clinical reasoning (5 items). The initial eigenvalues showed that the first factor explained $51 \%$ of the variance, and the second factor explained $16 \%$ of the variance. The two-factor solution accounted for $66.84 \%$ of the total variance. Factor one measured students' assessment findings from the system. Higher scores indicated a higher level of assessment skill in data collection through the system. Factor two measured clinical reasoning in the nursing process. Higher scores indicated well-organized clinical decisions that are made pertinent to patient management, based on the assessment findings. Students demonstrate a higher score on clinical reasoning in the nursing documentation when students can identify/recognize a patient's problem by understanding pathophysiology and can manage any identifiable patient problems by providing appropriate nursing diagnosis/interventions. A higher mean score of CEND represents more competence in electronic nursing documentation. The overall CEND had acceptable reliability with Cronbach's alpha of .80 . 


\subsection{Data analysis}

The Statistical Package for the Social Sciences (SAS, version 9.4$)^{[?]}$ was used to analyze the quantitative data. Both descriptive and inferential statistics were utilized to compare demographics between the groups and to compare the competency of electronic nursing documentation. The KolmogorovSmirnov test was applied to test for normal distribution. Independent $t$-tests and the Mann-Whitney test were performed to identify the differences between the two groups (BS and ABS). In addition, analysis of covariance (ANCOVA) was used to compare the differences between the two groups, after controlling age as a confounding factor. For the qualitative data, qualitative content analysis ${ }^{[16]}$ was used to analyze both the faculty and students' perceptions of AEHRs regarding electronic nursing documentation. All interviews and the focus group discussion were transcribed verbatim for analysis. The two researchers were independently coded. The transcribed text was carefully read, and patterns were identified. During the process of coding, data segments were grouped based on commonalities in order to facilitate insight and comparison. ${ }^{[17]}$ The researchers identified patterns related to the faculty's and students' perceptions of introducing AEHRs for teaching/learning electronic nursing documentation. An iterative process continued throughout the entire analysis process to ensure that data were authentically represented.

\section{Results}

\subsection{Quantitative findings}

Although both the intervention (ABS, $n=7$ ) and comparison groups $(\mathrm{BS}, \mathrm{n}=34)$ were second-year undergraduate students in the same college, the age differences between the groups were significant $(p<.001)$. The ABS participants' ages ranged from 24-46 years old, while the BS participants' ages ranged from 19-21 years old. The majority of the ABS students $(n=6)$ and BS students $(n=31)$ are female. Although all ABS students were Caucasian, two-thirds of the BS students were Caucasian $(n=24,70.6 \%, p=.61$; see Table 1).

Table 1. Students' demographics for quantitative data

\begin{tabular}{|c|c|c|c|c|}
\hline \multicolumn{2}{|c|}{ Characteristics } & \multirow{2}{*}{$\begin{array}{l}\text { ABS Group (Intervention, } \mathbf{n}=7 \text { ) } \\
1(14.3 \%)\end{array}$} & \multirow{2}{*}{$\begin{array}{l}\text { BS Group(Control, } \mathbf{n}=\mathbf{3 4}) \\
34(100 \%)\end{array}$} & \multirow[t]{2}{*}{ Chi-squares ( $p$ value) } \\
\hline \multirow{5}{*}{ Age } & $18-24$ years old & & & \\
\hline & 25-34 years old & 3 (42.9\%) & $0(0 \%)$ & \multirow{4}{*}{$<.001^{*}$} \\
\hline & 35-44 years old & $2(28.6 \%)$ & $0(0 \%)$ & \\
\hline & 45-54 years old & $1(14.3 \%)$ & $0(0 \%)$ & \\
\hline & 55-64 years old & $0(0 \%)$ & $0(0 \%)$ & \\
\hline \multirow{5}{*}{ Ethnicity } & Caucasian & 7 (100\%) & $24(70.6 \%)$ & \multirow{5}{*}{.605} \\
\hline & Hispanic & $0(0 \%)$ & $2(5.9 \%)$ & \\
\hline & Asian & $0(0 \%)$ & $1(2.9 \%)$ & \\
\hline & African American & $0(0 \%)$ & $4(11.8 \%)$ & \\
\hline & Other & $0(0 \%)$ & $3(8.8 \%)$ & \\
\hline \multirow{2}{*}{ Gender } & Female & $6(85.7 \%)$ & $31(91.2 \%)$ & \multirow{2}{*}{.657} \\
\hline & Male & $1(14.3 \%)$ & $3(8.8 \%)$ & \\
\hline
\end{tabular}

${ }^{*} p<.05$

After the intervention group (ABS students) had received learning opportunities with electronic nursing documentation skills within AEHRs for one semester (the 2nd term: Spring 2018), both the BS students (control group) and the ABS students' competency with electronic nursing documentation were compared. Both the BS and the ABS program have the same curriculum except for the different timeline (ABS: 5 terms (one and half years) vs. BS: 4 years).

Table 2 reveals that with regard to the competency in electronic nursing documentation as measured by the CEND, the intervention group (ABS) shows a higher mean rank for all items than the comparison group (BS). Its results did not

Published by Sciedu Press show statistically significant differences in the total CEND score between the two groups. However, differences were significant in the third item (gathering a patient's subjective health information, $p=.002$ ) between the groups. In addition, the third item (gathering a patient's subjective health information, $p=.029$ ) shows a significant difference between the groups, after controlling age as a confounding variable.

\subsection{Qualitative findings}

Three key patterns were shared by the faculty and students: (1) Benefit and challenges (student (cost) vs. faculty (lack of resources)); (2) Impact of AEHRs; and (3) Recommendations for the future adoption of AEHRs. The seven-nursing 
faculty each participated in a one-on-one interview, and the nine ABS students participated in a focus group. The characteristics of the participants are shown in Table 3. As indicated by the tables, all faculty participants were female, with a majority being Caucasian. The age of the nursing faculty ranged from 41-57 years old. Their teaching experience ranged from
2-12 years. Among the nine student participants, the majority were female (89\%) and Caucasian (89\%). The age of the students ranged from 25-46 years old. Three patterns emerged from the interviews and the focus group (see Table 3).

Table 2. The mean score and mean rank of competency of electronic nursing documentation (CEND scale) by groups (Mann-Whitney U Test Results and ANCOVA results)

\begin{tabular}{|c|c|c|c|c|}
\hline \multirow{2}{*}{ Items } & $\begin{array}{l}\text { ABS group } \\
(n=7)\end{array}$ & $\begin{array}{l}\text { BS group } \\
(n=34)\end{array}$ & \multirow{2}{*}{$\begin{array}{l}\text { ANCOVA } \\
p \text { value }\end{array}$} & \multirow{2}{*}{$\begin{array}{l}\text { Mann- } \\
\text { Whitney } \\
\text { U Test } \\
p \text { value }\end{array}$} \\
\hline & \multicolumn{2}{|c|}{$\begin{array}{l}\text { Mean score (mean rank } \\
\text { score) }\end{array}$} & & \\
\hline The student can describe the pathophysiology of presenting problems. & $\begin{array}{l}3.33 \\
(22.07)\end{array}$ & $\begin{array}{l}3.22 \\
(20.78)\end{array}$ & .206 & .792 \\
\hline $\begin{array}{l}\text { The student knows how to collect a patient's objective health information } \\
\text { cued by the system. }\end{array}$ & $\begin{array}{l}3.57 \\
(28.64)\end{array}$ & $\begin{array}{l}2.87 \\
(19.43)\end{array}$ & .230 & .062 \\
\hline $\begin{array}{l}\text { The student knows how to collect a patient's subjective health information } \\
\text { using the system. }\end{array}$ & $\begin{array}{l}3.52 \\
(33.43)\end{array}$ & $\begin{array}{l}2.73 \\
(18.44)\end{array}$ & .029 & $.002^{*}$ \\
\hline $\begin{array}{l}\text { Overall, the student can apply proper assessment skills to collect a } \\
\text { patient's current health information through the system. }\end{array}$ & $\begin{array}{l}3.67 \\
(27.07)\end{array}$ & $\begin{array}{l}3.27 \\
(19.75)\end{array}$ & .192 & .135 \\
\hline $\begin{array}{l}\text { The student identifies/recognizes patient's problems (e.g., abnormalities/ } \\
\text { early signs or symptoms from the collected patient information). }\end{array}$ & $\begin{array}{l}3.81 \\
(26.43)\end{array}$ & $\begin{array}{l}3.38 \\
(19.88)\end{array}$ & .307 & .184 \\
\hline The student can prioritize identified patient problems. & $\begin{array}{l}3.81 \\
(22.57)\end{array}$ & $\begin{array}{l}3.67 \\
(20.68)\end{array}$ & .817 & .700 \\
\hline $\begin{array}{l}\text { The student can provide the appropriate nursing diagnosis for the } \\
\text { identified patient problems. }\end{array}$ & $\begin{array}{l}3.90 \\
(23.21)\end{array}$ & $\begin{array}{l}3.69 \\
(20.54)\end{array}$ & .985 & .586 \\
\hline $\begin{array}{l}\text { The student can select appropriate nursing intervention for the identified } \\
\text { patient problems. }\end{array}$ & $\begin{array}{l}3.48 \\
(27.14)\end{array}$ & $\begin{array}{l}3.06 \\
(19.74)\end{array}$ & .399 & .132 \\
\hline Total mean score of CEND scale & $\begin{array}{l}3.64 \\
(26.79)\end{array}$ & $\begin{array}{l}3.24 \\
(19.81)\end{array}$ & .201 & .16 \\
\hline
\end{tabular}

\subsubsection{Benefits and challenges}

This theme includes a feeling of benefits and challenges of adopting an AEHRs. The subthemes involve reducing the gap between education and practice, equipment/cost/training, resistances/dissatisfaction, and quality of AEHRs. A majority of faculty and students reported that AEHRs could be beneficial, but also it could be challenging, such as the cost, lack of resources (training), equipment (computers at nursing labs), technical support from the IT team) and support from other faculty and faculty leadership. Faculty perceived that adoption of AHERs is a process of modifying existing teaching strategies, involving redesign a course, train students with AEHRs, and collaborate/interact with other faculty/staff (IT team). During this process, the faculty has a feeling of challenges and dissatisfaction related to inadequate equipment, lack of training, and support. In addition, faculty reported that all of the faculty were not on board with the adoption of an AEHRs. Due to this inconsistent adoption between courses and faculty, students perceived the adoption of an AEHRs was not successful as redundant assignments after clinical rotations at the hospitals. Also, students reported the gap between current AEHRs and the EHR system at the hospitals. The more substantial gaps could lead to insufficient learning from AEHRs. Students reported a high quality of AEHRs could enhance their learning, particularly critical thinking in the nursing process.

"It could be beneficial. I think it bridges the classroom and clinical, which is the big piece that I feel like we're sometimes missing." (Faculty \#2)

"Some of my challenges are to make sure all of the faculty were on board with it. If not, I think it gets really hard for the students." (Faculty \#5)

"Even when we saw real patients and used DocuCare, I was just clicking through and submitting it. I wasn't like thinking." (Student \#4) 
Table 3. Faculty/student demographics for qQualitative data

\begin{tabular}{lllll}
\hline Characteristics & Faculty $\mathbf{( n =}$ ) & Frequencies $\mathbf{( \% )}$ & Students $\mathbf{( n}=\mathbf{9})$ & Frequencies (\%) \\
\hline \multirow{3}{*}{ Age } & 35-44 years old & $4(57.2 \%)$ & $20-30$ years old & $2(22.2 \%)$ \\
\multirow{2}{*}{ Race/Ethnicity } & 45-54 years old & $2(28.6 \%)$ & $31-40$ years old & $5(55.5 \%)$ \\
\multirow{2}{*}{ Gender } & 55-64 years old & $1(14.3 \%)$ & $41-50$ years old & $1(11.1 \%)$ \\
& Caucasian & $7(100 \%)$ & Caucasian & $9(100 \%)$ \\
\multirow{2}{*}{ Education } & Female & $7(100 \%)$ & Female & $8(88.9 \%)$ \\
& Male & $0(0 \%)$ & Male & $1(11.1 \%)$ \\
& Completed MS degree & $4(57.2 \%)$ & Completed BS degree & $9(100 \%)$ \\
\hline
\end{tabular}

\subsubsection{The impact of AEHRs}

This pattern is extensive evidence that early adoption of AEHRs affected students' learning regarding nursing documentation both positively and negatively. The positive impact includes the totality of features and characteristics of the system that bears its ability to satisfy stated or implied needs. Negatively, student participants expressed their feeling that the skills in critical thinking have declined, as AEHRs has played a role in nursing documentation. Also, this pattern includes that the system is different from the real EHR system at hospitals. Faculty reported more likely that students could learn conceptualizing a patient's condition through the AEHRs. Students described that their learning could be optimized with an accurate representation of EHRs in the clinical setting. Even two students mentioned preferring to learn with paper documentation because the quality of current AEHRs was inadequate.

"I think the students would benefit from information at their fingertips." (Faculty \#1)

"I don't think DocuCare is an accurate representation of what we see in the clinical setting." (Student \#5)

"So, I was just clicking, clicking, clicking, and not actually learning or thinking how to think with these made-up patients in the simulation critically." (Student \#4)

\subsubsection{Recommendations for the future adoption of AEHRs}

This pattern includes meaningful use of AEHRs as recommendations for future adoption. Faculty described that the utilization of an AEHR needs to be specific with a plan about how to use it in the curriculum. Both students and faculty participants suggested that AEHRs should be more challenging to make them think critically and become a more sophisticated tool for learning nursing documentation. As mentioned in previous sections 3.1 and 3.2, a smaller difference between current AEHRs and EHRs at the hospitals can provide students with a learning environment in which to be familiar with the system, and to practice necessary skills for the conceptualization of patients through the system and electronic nursing documentation. The sophisticated AEHRs could help students in the tradition to practice related to the electronic nursing documentation.

"I would expect to have a laptop at each bed so that they can go through the experience and simulate taking care of a patient. It doesn't have to be a high-fidelity simulation, but we should be able to do low-fidelity simulation still and utilize DocuCare and the documentation." (Faculty \#6)

"You just end up clicking through to get an answer. But then again, one of the best parts about it is that you didn't have to think." (Student \#5)

\section{Discussion}

This pilot study explored the faculty's and students' perceptions of introducing AEHRs for teaching/learning electronic nursing documentation, and it assessed the outcomes of AEHRs on nursing students' competency with electronic nursing documentation. The qualitative findings found that the faculty and students perceived that AEHRs could help students' learning regarding nursing documentation. The most significant benefit of the early adoption of AEHRs was to provide students' learning opportunities to access and practice with patient data. However, the quantitative findings were not sufficient enough to support that AHERs could improve students' learning competence of electronic nursing documentation, due to the small sample size. Unfortunately, 41 participants (34 in the BS group and 7 in the ABS group) were not ideal for maintaining the statistical power for the primary outcome.

The current literature shows that students are confident with their electronic nursing documentation after students explore AEHRs, ${ }^{[5,18]}$ although several challenges/barriers were addressed in the current literature such as a lack of training, inadequate technical support, and cost. ${ }^{[5,7,9,19]}$ One of the barriers, some faculty felt that learning electronic documentation was not a priority. ${ }^{[5]}$ Several studies show that a majority 
of faculty reported that they are self-taught regarding nursing documentation using the EHR system, and their barriers were lack of resources that lead to the slow adoption of AEHRs. ${ }^{[7,9,18]}$ In addition, this study found that nurse educators still faced several challenges; a small group of nursing faculty involved, a lack of training, and a lack of a specific plan in curriculum development related to AEHRs.

Faculty and students perceived the adoption of an AEHRs was unsuccessful, although both faculty and students agreed with the benefits of an AEHRs, from the qualitative findings. Faculty described this unsuccessful adoption was associated with that all of the faculty were not on board with the adoption of AEHRs. This study found faculty's active involvement was necessary for successful adoption. The faculty perceived the challenges and barriers due to the lack of consensus on how faculty can utilize the AEHRs in each course. Unfortunately, there were no guidelines or specific recommendations on how to implement AEHRs. More importantly, qualitative findings showed that successful adoption required a step-by-step process with a well-designed plan. We adopted the AEHRs with the belief that the AEHRs could create a productive environment for nursing students to interact with the EHR systems without a well-designed plan. Without a good plan, students in the intervention group faced inconsistent adoption between courses and faculty, and the AEHRs could not be optimized. We learned the key elements of the successful adoption of AEHRs could be highly associated with active involvement from faculty, support from colleagues, administrative leadership, and establishing implementation plans/strategies with goals.

With regard to the quantitative findings in this study, the difference in the total CEND score was not statistically significant between the intervention group and the comparison group $(p=.16)$. As earlier mentioned, this finding might be related to the small sample size that was not sufficient enough to provide the outcomes of an AEHRs. The insignificant results could be explained by the adoption of AEHRs without a well-designed plan on how to implement it into the curriculum. Interestingly, from the qualitative findings for the students, the inadequate quality of AEHRs was one of the biggest reasons for unsuccessful adoption. Even two students described that learning with paper documentation would be better due to the inadequate quality of current AEHRs. Students considered an AEHRs as redundant work/assignments after clinical rotations at the hospitals. AEHRs should be more challenging to make students think critically and become a more sophisticated tool for learning nursing documentation. When the sophisticated AEHRs is an accurate representation of EHRs in the clinical settings, it can help students in the tradition to practice related to the electronic nursing documentation.

From the quantitative findings, there was a significant difference between the two groups in the third item (gathering a patient's subjective health information, $p=.002$ ). This means that the early adoption of AEHRs could help students to collect a patients' health information through the system even though it may not impact their critical thinking on a patient's care. The essential attributes of critical thinking are interpretation, analysis, evaluation, inference, explanation, and self-regulation. ${ }^{[20]}$ It could be more efficient if nurse educators use AEHRs for synthesizing knowledge in patient care. Within AEHRs, faculty and nursing students should be not only familiar with AEHRs for data entry but also competent with the meaningful use of AEHRs in learning/teaching throughout the curriculum. ${ }^{[7,9]}$ The Health Information Technology for Economic and Clinical Act also supports the "meaningful use" of EHRs. According to the CDC's report, ${ }^{[21]}$ meaningful use is defined by the use of EHRs in a meaningful manner that provides for the electronic exchange of health information to improve the quality of care. Similarly, the concept of "meaningful use of AEHRs" can be defined by the use of AEHRs in a manner that enhances students' learning for synthesizing knowledge in patient care. With more sophisticated/optimized AEHRs, it could enhance students' learning how to critically think with the cases in the simulation and class activities, rather than just clicking and clicking. The sophisticated/optimized AEHRs implies a good representation of what we see at the hospitals (e.g., Epic, Medtech, etc.).

Limitations of this study include that it was conducted without pre-assessment, non-randomized study design between the control group and the intervention group, and in only one university whose end sample size was small. Future studies are needed to validate the current findings using a larger sample with a more significant sample with several settings, pre-assessment, and random sampling technique.

\section{Conclusions}

This study revealed that the successful adoption of an AEHRs includes many steps that can be used to create positive improvements. Although the quantitative findings were not sufficient enough to provide a significant outcome of the adoption of an AEHRs, the qualitative findings revealed that the meaningful use of AEHRs was recommendations for future adoption. The key elements of the meaningful use of AEHRs are active involvement from faculty, support from colleagues, and administrative leadership, and establishing implementation plan/strategies with goals. These findings were beneficial to prepare students and nursing educators for the future of health information technology. Meaningful 
adoption of AEHRs will help in building the competence of undergraduate nursing students in electronic nursing documentation and improve patient care.

\section{CONFLicts OF InTEREST Disclosure}

The authors declare that there is no conflict of interest.

\section{REFERENCES}

[1] American Hospital Association - Annual Survey Information Technology Supplement [Internet].; 2017. Available from: https://dashboard.healthit.gov/quickstats/pages/ce rtified-electronic-health-record-technology-in-hos pitals.php

[2] Hebda T, Calderone TL. What nurse educators need to know about the TIGER initiative. Nurse Educ. 2010 April 01; 35(2): 56-60. PMid:20173588 https://doi.org/10.1097/NNE.0b013e3181 ced83d

[3] Cronenwett L, Sherwood G, Barnsteiner J, et al. Quality and Safety Education for Nurses. Nurs Outlook. 2007 June 01; 55(3): 122-31. PMid:17524799 https://doi.org/10.1016/j.outlook. 2007 .02 .006

[4] The Quality and Safety Education for Nurses (QSEN) Competencies; 2016 [cited 06/01/2020]. Available from: https://qsen.org/com petencies/pre-licensure-ksas/\#informatics

[5] Baxter PM, Andrew LA. Successful Integration of an Academic Electronic Health Record Into the Curriculum of an Associate Degree Nursing Program. Nurs Educ Perspect. 2018 August 01; 39(4): 250-2. PMid:29863548 https://doi.org/10.1097/01. NEP.0000000 000000255

[6] Chung J, Cho I. The need for academic electronic health record systems in nurse education. Nurse Educ Today. 2017 July 01; 54: 83-8. PMid:28500984 https://doi.org/10.1016/j.nedt. 2017.04 .018

[7] Authors. The need for academic electronic health record systems in nurse education. Nurse Educ Today. 2017 July 01; 54: 83-8. PMid:28500984 https://doi.org/10.1016/j.nedt. 2017.04 .018

[8] Herbert VM, Connors H. Integrating an Academic Electronic Health Record: Challenges and Success Strategies. Comput Inform Nurs. 2016 August 01; 34(8): 345-54. PMid:27326804 https ://doi .or g/10.1097/CIN.0000000000000264

[9] Sorensen J, Campbell L. Curricular Path to Value: Integrating an Academic Electronic Health Record. J Nurs Educ. 2016 December 01; 55(12): 716-9. PMid:27893909 https://doi.org/10.3928/ 01484834-20161114-10

[10] Malane EA, Richardson C, Burke KG. A Novel Approach to Electronic Nursing Documentation Education: Ambassador of Learning Program. J Nurses Prof Dev. 2019 December 01; 35(6): 324-9.
PMid:31651554 https://doi.org/10.1097/NND. 0000000000 000587

[11] Whittenburg L, Meetim A. Electronic Nursing Documentation: Patient Care Continuity Using the Clinical Care Classification System (CCC). Stud Health Technol Inform. 2016; 225: 13-7.

[12] Jeffries PR, Rogers KJ. Theoretical framework for simulation design In: Jeffries PR, editor. From conceptualization to evaluation Simulation in nursing education. 2nd ed. New York: National League for Nursing. 2012. p. 25-42.

[13] Faul F, Erdfelder E, Buchner A, et al. G*Power. 2013.

[14] Polit DE, Beck CT. Trustworthiness and Integrity in Qualitative Research. In: in D.E. Polit \& C.T. Beck Nursing Research: Generating and Assessing Evidence for Nursing Practice. Philadelphia: Wolters Kluwer, Lippincott Williams and Wilkins; 2017. 557-575.

[15] Authors. Development and Psychometric Properties of the Competency of Electronic Nursing Documentation in Nursing Education. Nursing Education Perspectives. (In review)

[16] SAS Institute Inc. SAS/ACCESS $® 9.4$ Interface to ADABAS: Reference. 2019.

[17] Hsieh HF, Shannon SE. Three approaches to qualitative content analysis. Qual Health Res. 2005 November 01; 15(9): 1277-88. PMid:16204405 https://doi.org/10.1177/10497323052766 87

[18] Miles MB, Huberman AM. Qualitative data analysis: An expanded sourcebook. 2nd ed. Thousand Oaks, CA, US: Sage Publications, Inc.; 1994.

[19] Titzer JL, Swenty CF. Integrating an academic electronic health record in a nursing program: creating a sense of urgency and sustaining change. Nurse Educ. 2014 October 01; 39(5): 212-3. PMid:25137446 https://doi.org/10.1097/NNE. 0000000000 000064

[20] King TS, Schubert C, Pittman O, et al. Use of an Academic Electronic Health Record With an Interprofessional Simulation for Advanced Practice Nursing Students. Nurs Educ Perspect. 2020 February 19.

[21] Facione PA. Critical thinking: A statement of expert consensus for purposes of educational assessment and instruction. . Millbrae, California, IL: California Academic Press; 1990.

[22] Public Health and Promoting Interoperability Programs (formerly, known as Electronic Health Records Meaningful Use. [Internet].; 2019 [cited 02/01/2020]. Available from: https://www.cdc.gov/ ehrmeaningfuluse/introduction.html 